\title{
АВТОМАТИЧЕСКОЕ ВИЗИРОВАНИЕ ЭЛЕКТРОННЫХ ДОКУМЕНТОВ В БИЗНЕС-ПРОЦЕССАХ ПРИКЛАДНЫХ РЕШЕНИЙ ПЛАТФОРМЫ «1С:ПРЕДПРИЯТИЕ 8.3»
}

\author{
В. А. Лебедев \\ Институт экономики и предпринимательства \\ Уфимский государственный авиаиионный технический университет
}

Поступила в редакцию 20.03.2019 г.

\begin{abstract}
Аннотация. Предлагается разрабатывать бизнес-процессы с автоматическим визированием документов на платформе «1С: Предприятие 8.3» для различных отраслей экономики, и сфер деятельности организаций, используя язык программирования $1 \mathrm{C}$, язык запросов SQL и язык VBA офисных приложений. B результате ожидается повышения надежности хранения электронных документов и сокращение времени ведения документооборота в организациях, что позволит эффективно решать задачи программы цифровой экономики РФ. Ключевые слова: прикладные решения 1С:Предприятие, бизнес-процессы, задачи, карты маршрута, макеты Active document, события, обработчики событий.
\end{abstract}

\section{ВВЕДЕНИЕ}

Зарубежные ERP-системы (SAP R/3 co средой Бизнес-Анализатор, Oracle Applications, Microsoft Dynamics и пр.) содержат в своем арсенале более 800 разработанных бизнес-процессов для нескольких отраслей промышленности и видов бизнеса [1]. Для более тонкой настройки бизнес-процессов (БП) системный администратор должен владеть внутренним языком программирования (например, АВАР Workbench в SAP R/3 $[2,3])$. Однако усиливающаяся глобализация и конкуренция, а для РФ - это еще и санкции, постоянно требуют ответных реакций компаний (организаций), и разработанные БП становятся эффективным механизмом, призванным решать вопросы улучшения результативности, расширения возможностей и способности адаптации компаний к меняющимся условиям [4].

Среди отечественных информационных систем, прежде всего, следует выделить прикладные решения компании «1C», такие как, «1C: Управление торговлей», «1C: Зарплата и управление персоналом», «1C: Бухгалтерия предприятия», «1C: Комплексная автомати-

() Лебедев В. А., 2019 зация», «1C: ERP Управление предприятием», «1C: Корпоративный университет» и прочие, отвечающие требованиям цифровизации экономики и иных сфер деятельности [5]. Каждое прикладное решение содержит платформу «1C: Предприятие 8.3» с объектами, настроенными на конкретные функциональные возможности деятельности компании, и работающими в режимах: Конфигуратор и Пользователь. В первом создаются объекты прикладного решения (Справочники, Документы, Регистры, Задачи, Бизнес-процессы и пр.), а во втором - они используются (заполняются данными), хотя могут встречаться и предопределенные значения у объектов.

Во многих прикладных решениях (демо-версиях) имеются свои наборы готовых к использованию бизнес-процессов, основываясь на которых программист может научиться создавать свои бизнес-процессы. В табл. 1 представлены некоторые прикладные решения с указанием количества готовых в них бизнес-процессов.

Из табл. 1 видно, что существующих бизнес-процессов явно недостаточно, если сравнить их с количеством БП в зарубежных ERP-решениях. При этом также для более тонкой настройки существующих биз- 


\section{B. А. Лебедев}

Таблица 1

\begin{tabular}{|l|c|}
\hline \multicolumn{1}{|c|}{ Прикладное решение } & Количество бизнес-процессов \\
\hline 1С: Документооборот 8 КОРП 2.1 & 13 \\
\hline 1С: ЕRР 2.4 & 6 \\
\hline 1С: Комплексная автоматизация 2.4 & 6 \\
\hline 1С: Управление торговлей 11.4 & 6 \\
\hline 1С: Управление производственным предприятием 1.3 & 1 \\
\hline 1С: Зарплата и управление персоналом КОРП 3.1; & \\
1С: Зарплата и кадры государственного учреждения 3.1 & \\
\hline 1С: Управление холдингом 3.0; & \\
1С: Бухгалтерия предприятия КОРП 3.0, & 0 \\
1С: Зарплата и кадры бюджетного учреждения 1.0, \\
1С: Государственные и муниципальные закупки 1.1 \\
1С: Корпоративный университет 3.0, \\
1С: Образовательная организация 3.0, 1С: Экзаменатор 3.0
\end{tabular}

нес-процессов или создания новых требуется знать объектно-ориентированный язык программирования 1C, язык запросов SQL и язык VBA приложений Word, Excel для изменения офисных документов. Но, все же, представленные отечественные разработки постоянно совершенствуется (для них выпускаются новые редакции и релизы), и они отвечают современным требованиям информатизации и автоматизации деятельности компаний. Среди представленных в таблице программных продуктов следует выделить «1С: Документооборот 8 КОРП», содержащий 13 готовых бизнес-процессов общего назначения. К ним можно прикреплять любые внутренние и внешние документы, а также выбрать их из списка и создать файлы на основе шаблонов для исполнителей бизнес-процессов (рис. 1-2).

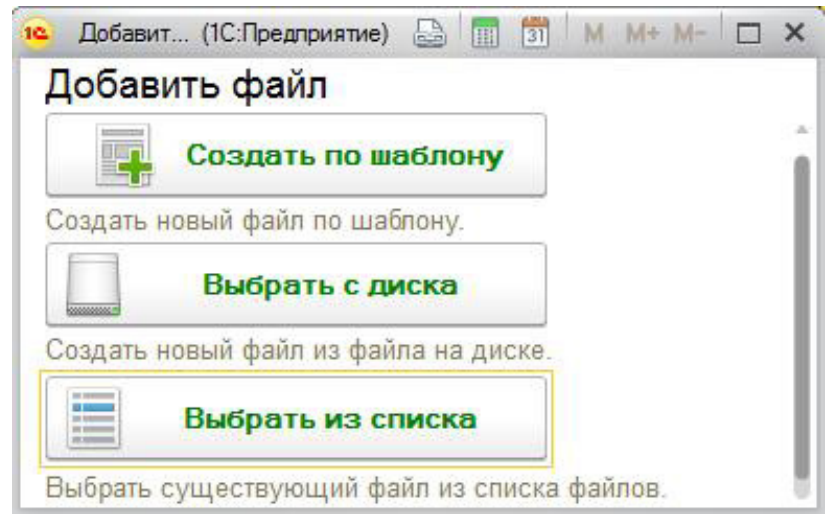

Рис. 1. Диалог добавления файлов
Во всех прикладных решениях 1С электронные документы (платежные ведомости, расходные кассовые ордера, товарно-транспортные накладные, акты выполненных работ и пр.) создаются в системе, распечатываются, подписываются ответственными лицами и подшиваются к другим бумажным документам для хранения в папках или передаются клиентам (поставщикам). Если же потребуется перевести подписанные документы в электронную форму, то обращаются к процессу сканирования и распознавания. В статье предлагается совместить эти процессы в одном, то есть подготавливать электронные документы в бизнес-процессах прикладных решениях и автоматически визировать их подписями исполнителей, а, если необходимо, то пересылать их клиентам в государственные и налоговые органы.

\section{МАТЕРИАЛЫ И МЕТОДЫ}

Запрограммированный БП определяет последовательность действий сотрудников (исполнителей) организации на основе разработанной схемы - Карты маршрута. По мере продвижения от блока к блоку по карте маршрута создаются задачи (автоматически или программно), адресованные определенным исполнителям. Кроме этого для связки Бизнес-процесс - Задача обычно используется ре- 
Автоматическое визирование электронных документов в бизнес-проиессах прикладных решений ...

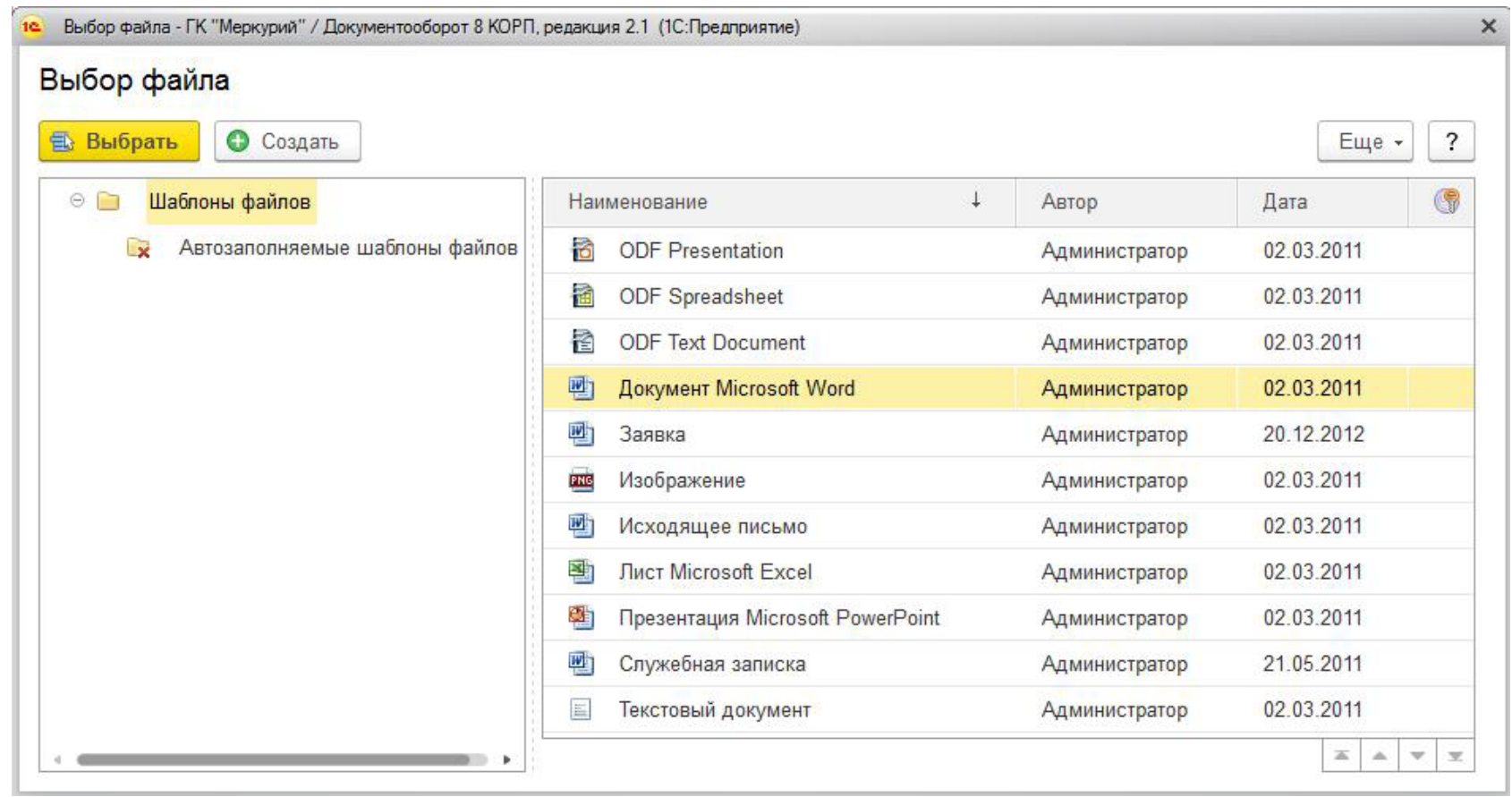

Рис. 2. Диалог создания файла на основе шаблона

гистр сведений с одноименными измерениями как у объекта Задача, а также дополнительные справочники, документы и прочие объекты с пользовательскими и стандартными реквизитами, определяющими специфику работы системы. Стандартные реквизиты - это предопределенные поля объектов самой системы. Следует отметить, что объекты Задача и Бизнес-процесс связаны между собой связью «многие-ко-многим», а платформа «1С: Предприятие 8.3» поддерживает постреляционную и многомерную модели данных [6].

Программный код объекта Бизнес-процесс, работающий на клиенте и на сервере, размещается в модуле объекта и модулях форм, а у объекта Задача - в модуле объекта, модуле формы списка и модуле менеджера [7-10]. Также программный код может выноситься в общие модули, а для хранения глобальных значений, доступных всем объектам конфигурации, используются константы или общие реквизиты.

Рассмотрим бизнес-процесс ТехПроцессКонтроля по формированию и сохранению документа маршрутной карты технологического процесса на предприятии. Технологический процесс включает в себя доставку деталей в цех и внешний осмотр их термистом. Если все в норме, то термист приступает к одному из трех видом операции отжига (задание он получает от мастера, который запускает бизнес-процесс). После отжига детали поступают контролеру, который анализирует качество отжига. Если качество их не было достигнуто, то они вновь возвращаются термисту, с требованием дополнительной операции. Если состояние деталей контролера удовлетворило, то они поступают мастеру, который передает их в другой цех.

Ниже представлена карта маршрута бизнес-процесса (рис. 3), а также схемы модулей объектов Бизнес-процесс и Задача (рис. 4-9).

Ранее маршрутная карта технологического процесса перемещалась вместе с деталями от цеха к цеху, от исполнителя к исполнителю, но, используя созданный бизнес-процесс, можно сформировать ее и сохранить в конце работы бизнес-процесса со всеми подписями исполнителей и иными значениями атрибутов. При этом все подписи исполнителей предварительно сохраняются в png-формате на прозрачном фоне на диске или в атрибутах специального справочника.

Поэтапная работа с БП может быть описана следующим алгоритмом. Автор БП в режиме Пользователя запускает форму элемента БП, заполняет поле ДатаОкончания и выбирает из списка ФИО термиста (на- 


\section{B. А. Лебедев}

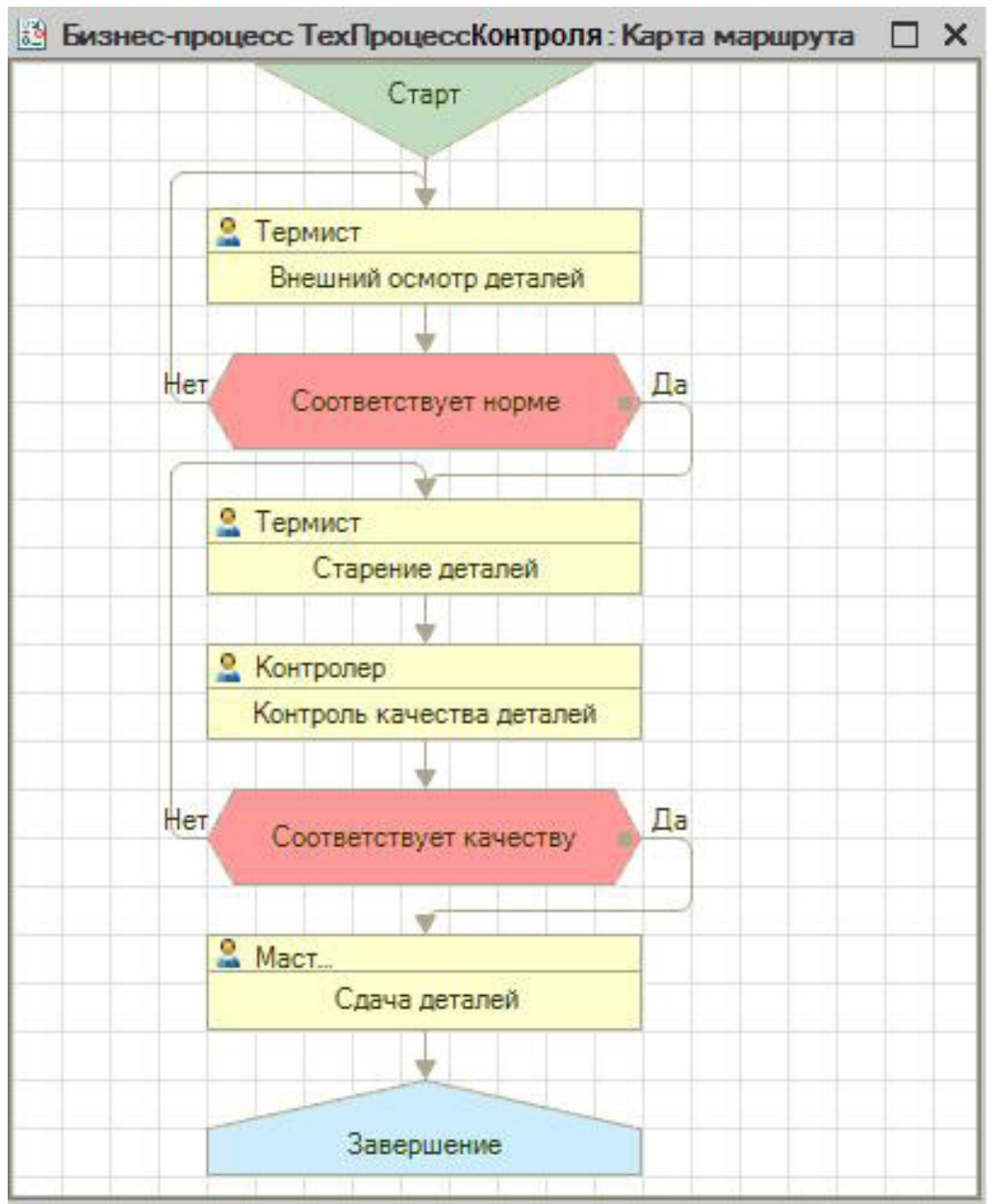

Рис. 3. Карта марирута бизнес-процесса

Модуль Формы бизнес-процесса "ТехПроцессКонтроля"

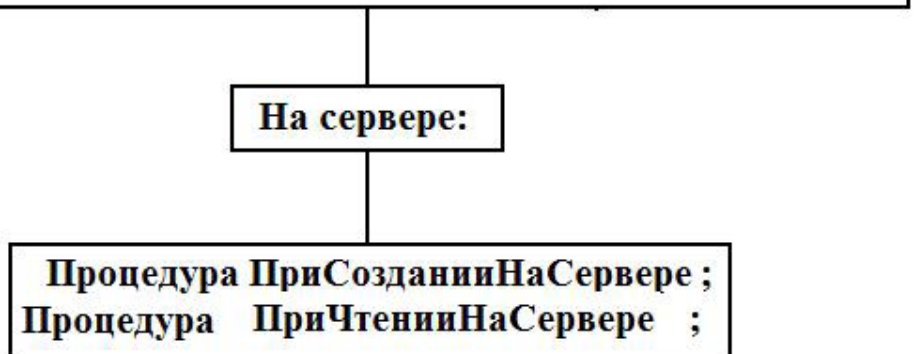

Рис. 4. Содержимое модуля формь бизнес-проиесса

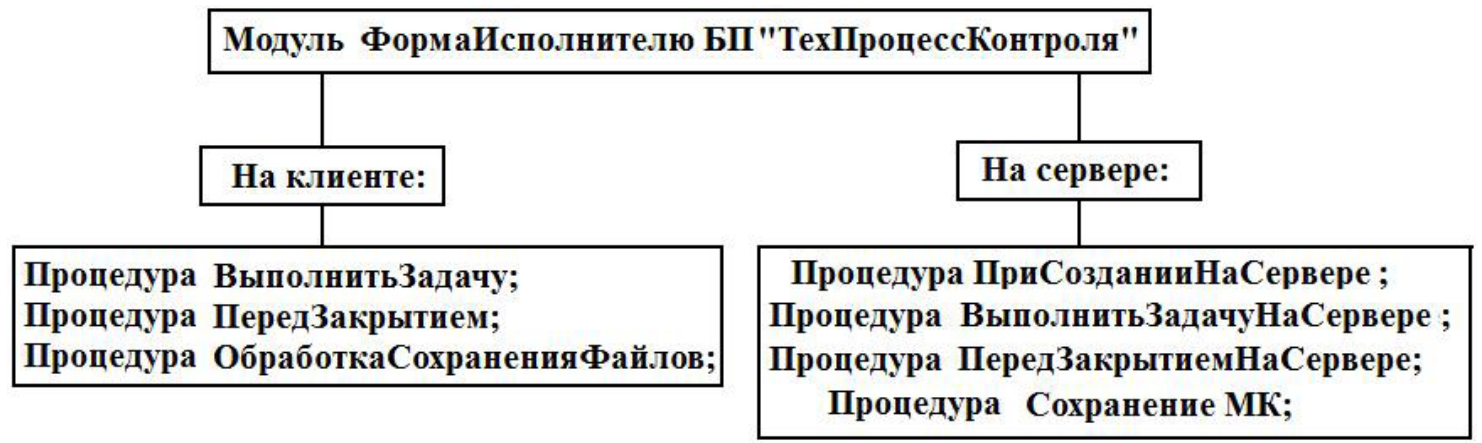

Рис. 5. Содержимое модуля ФормаИсполнителю БП 
Автоматическое визирование электронных документов в бизнес-проиессах прикладных решений ...

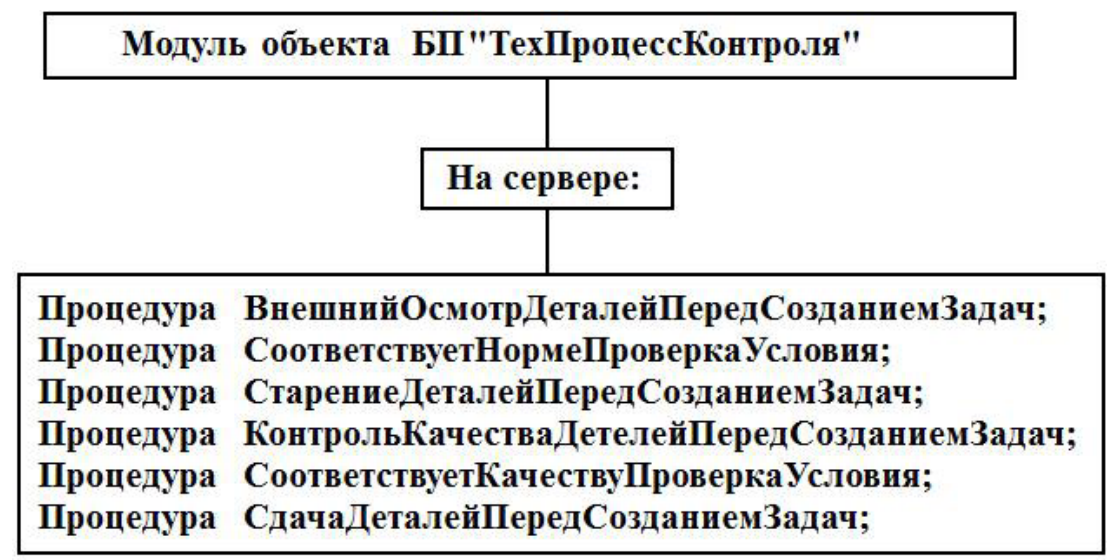

Рис. 6. Содержимое модуля объекта БП

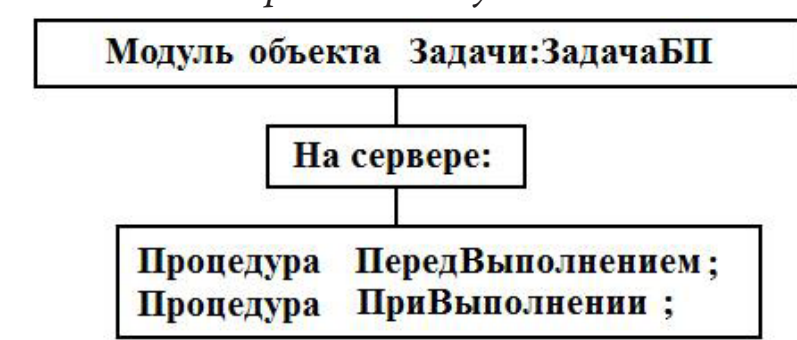

Рис. 7. Содержимое модуля объекта ЗадачаБП

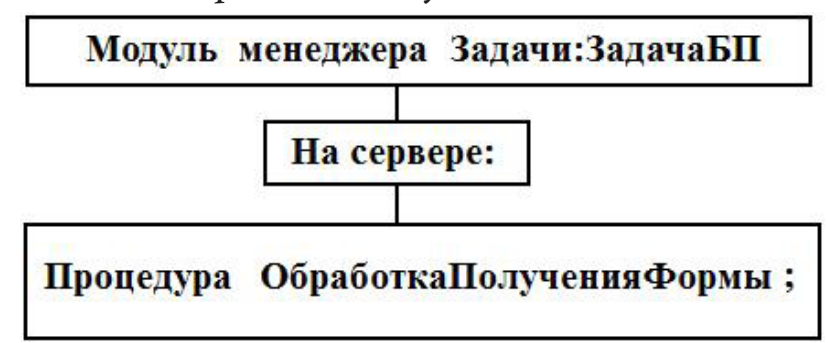

Рис. 8. Содержимое модуля менеджера ЗадачаБП

пример, Петрова П. П.), контролера (Галкину Г. Г.), мастера (Иванова И. И.), после чего нажимает кнопку «Стартовать и закрыть». На форме списка отобразится запущенный БП, при этом в процедуре ВнешнийОсмотрДеталейПередСозданиемЗадач модуля объекта будет создана задача для термиста. Поскольку система 1C сетевая, то термист должен под своим логином и паролем (за каждым исполнителем закреплена своя роль) войти в систему и выполнить сформированную задачу (дважды щелкнуть по ней). Отобразится ФормаИсполнителю БП, в которой термисту следует заполнить поля Комментарий и проставить/снять флаг Норма. Именно по этому флагу определяется переход вперед/назад на формирование новой задачи для контролера (блок СтарениеДеталей) или для термиста (назад в блок ВнешнийОсмотр). Значение из поля Комментарий будет скопировано в поле
Результат формы списка БП. После заполнения полей каждый исполнитель нажимает кнопку «Выполнить Задачу» (которая должна быть создана, как и атрибуты формы в режиме Конфигуратора), а затем закрывает форму задачи. Если флаг Норма не был установлен термистом, то в процедуре СоответствуетНормеПроверкаУсловия будет сформирована новая задача на повторную проверку деталей. Если же флаг был установлен, то в процедуpe СтарениеДеталейПередСозданиемЗадач будет сформирована задача для выполнения термистом одной из трех операций отжига. Далее в дело вступает контролер. В процедуре КонтрольКачестваДеталейПередСозданиемЗадач формируется задача для контролера (Галкиной). Она заходит под своим логином и паролем в систему и запускает задачу. Контролер проверяет качество деталей и решает, что с ними дальше делать. Она также остав- 


\section{В. А. Лебедев}

\begin{tabular}{|c|c|c|c|c|c|c|c|}
\hline \multicolumn{8}{|c|}{ МАРШРУТКА--ПРЕДЬЯВЛЕНИЕФ } \\
\hline & №.co & роводительн & о-докум & $\mathbf{x x x}$ & & -1 & \\
\hline \multicolumn{8}{|c|}{ Деталь: $\leq$ деталь $>\rightarrow \rightarrow$ Кол-во: $\mathbf{x x x}$} \\
\hline \multicolumn{8}{|c|}{ Дата: $\leq$ ТекушаяДата $>$ - Цех А $\rightarrow$ Материал: $\mathbf{x x x}$} \\
\hline \multirow{2}{*}{\multicolumn{8}{|c|}{ Подпись кладовщика: }} \\
\hline & & & & & & & \\
\hline Дата·загрузкия & Операцияж & 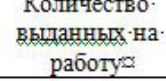 & $\begin{array}{l}\text { №- } \\
\text { сапкй }\end{array}$ & Оборудованиех & №-термограммыга & $\begin{array}{l}\text { Исполнитель' } \\
\text { (подпись) }\end{array}$ & $\begin{array}{l}\text { Контролер ๆ } \\
\text { (подпись) }\end{array}$ \\
\hline$\leq$ ТекущаяДата $>$ & поступлениех: & $<$ Kor $>x$ & $a$ & a & $\approx$ & $<$ термияст $>$ : & a \\
\hline$\leq$ ТекушаяДата $>$ & входной контроль'а & $\langle$ Kor $\rangle=$ & $z$ & $x$ & $a$ & $<$ термист $>\mathrm{s}$ & s \\
\hline 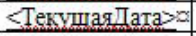 & старение & $<$ Kor $>0$ & $a$ & $\mathrm{xxx}$ & $8 a$ & $<$ термист>а & <контролер >а \\
\hline$\leq$ Текушаядата $>$ & $\begin{array}{c}\text { окончательная } \\
\text { қалказ }\end{array}$ & $<$ кол $>\infty$ & $a$ & $a$ & $a$ & $<$ термист>о & $<$ контролер >а \\
\hline$<$ ТекушаяДата $>$ a & сдачах & $\angle K O \pi>0$ & x & $a$ & $a$ & $<$ мастер>а & $a$ \\
\hline
\end{tabular}

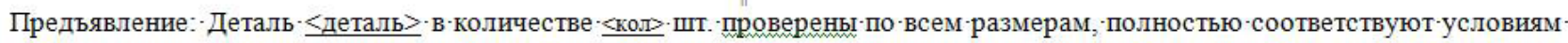
чертежа:и-ТУ.ศ

Подпись мастера: $\rightarrow \quad \rightarrow \quad<$ мастер $>$

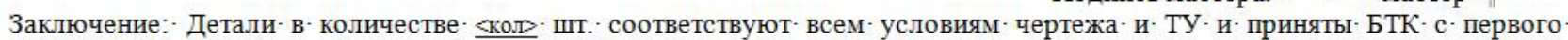
предъявления.ๆ

Подпись контролера: $\rightarrow<$ контролер $>$

Рис. 9. Макет маршрутной картьь

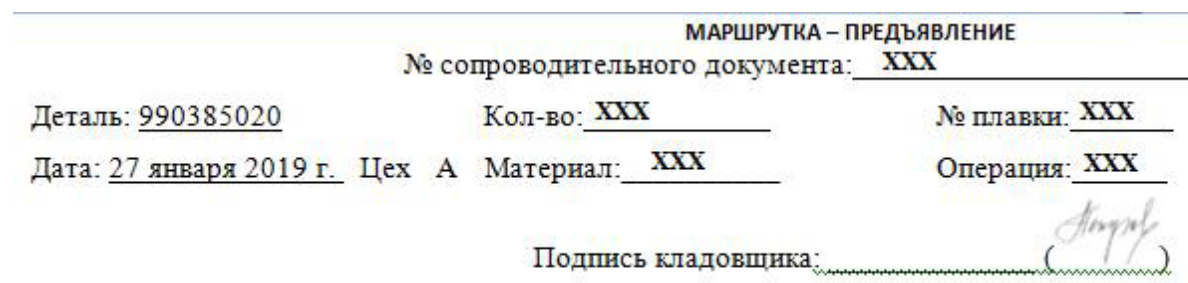

\begin{tabular}{|c|c|c|c|c|c|c|c|}
\hline Дата загрузки & Операция & $\begin{array}{c}\text { Количество } \\
\text { выданных на } \\
\text { работу }\end{array}$ & № садки & Оборудование & № термограммы & $\begin{array}{l}\text { Исполнитель } \\
\text { (подпись) }\end{array}$ & $\begin{array}{l}\text { Контролер } \\
\text { (подпись) }\end{array}$ \\
\hline 27 января 2019 г. & поступление & 110 & & & & & \\
\hline 27 января 2019 r. & $\begin{array}{l}\text { входной } \\
\text { контроль }\end{array}$ & 110 & & & & & \\
\hline 27 января 2019 r. & старение & 110 & & $\mathrm{xxx}$ & 8 & & on \\
\hline 27 январл 2019 r. & $\begin{array}{c}\text { окончательная } \\
\text { қалқа. }\end{array}$ & 110 & & & & & \\
\hline 27 января 2019 г. & сдача & 110 & & & & & \\
\hline
\end{tabular}

Предъявление: Деталь $\underline{990385020}$ в количестве $\underline{110}$ шт. проверены по всем размерам, полностью соответствуют условиям чертежа и ТУ.

Подпись мастера:

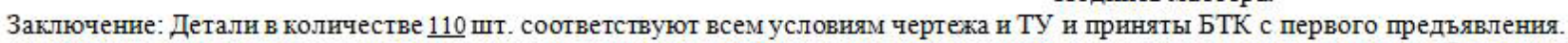

Подпнсь контролера:

Рис. 10. Заполненный подписями документ маршрутной карть

ляет свой комментарий и устанавливает/снимает флаг Качество. В зависимости от состояния этого флага процесс возвращается назад (формируется новая задача для термиста на иную термообработку - в блок СтарениеДеталей) или процесс продвигается вперед и передает управление мастеру - в блок СдачаДеталей. За это отвечает процедура Соответ-
ствуетКачествуПроверкаУсловия.

После выполнения задачи мастером автоматически будет сформирован документ Маршрутка.doc с подписями Петрова, Галкиной и Иванова на основе макета Active document (рис. 9-10), который должен быть предварительно создан в БП в режиме Конфигуратора. 
Автоматическое визирование электронных документов в бизнес-проиессах прикладных решений ...

\section{РЕЗУЛЬТАТЫ И ВЫВОДЫ}

Полученный результат заполнения маршрутной карты подписями исполнителей позволяет распространить его и на другие электронные документы и процессы, например на подписи экзаменационных билетов заведующим кафедрой, на промежуточную аттестацию студентов без использования бумажных копий экзаменационных и зачетных ведомостей и листов ответа на билеты студентов, на командировочные удостоверения и т.д.

Так в первом случае создается бизнес-процесс ПодписиРуководителя. Преподаватель готовит экземпляр билетов (dос-документ) и сохраняет его на сервере, запускает бизнес-процесс, прикрепляет его к форме бизнес-процесса и формирует задание для руководителя, который войдя под своим логином и паролем в систему «1С: Предприятие 8.3» просматривает билеты, и если замечаний нет, то завершает бизнес-процесс, при этом автоматически в doc-документе произойдет добавление текущей даты и подписей руководителя. В противном случае формируется новое задание для преподавателя, чтобы он смог исправить неточности, которые были сохранены в поле формы списка бизнес-процесса или в примечании doc-документа.

Во втором случае создается бизнес-процесс Экзамен (Зачет). В деканате создается электронный документ Экзаменационная (зачетная) ведомость без подписей и дат, но с ФИО и номерами зачеток студентов и сохраняется на сервере. Преподаватель запускает бизнес-процесс, прикрепляет этот документ к процессу, нажимает на кнопку, с помощью которой формируется электронный документ Протокол экзамена (зачета), прикрепляет его к бизнес-процессу, а затем открывает его для заполнения данными (номерами билетов и датой), и сохраняет на диске. При закрытии бизнес-процесса произойдет автоматическое заполнение документа Экзаменационная (зачетная) ведомость оценками и подписями экзаменатора из электронного документа Протокол экзамена (зачета). Также можно обойтись и без листов ответа на вопросы (все ответы будут сохранены в электронном виде), но для этого необходимо, чтобы у каждого студента был планшет или компьютер, подключенный к сети.

В любом документе можно автоматически проставлять не только подписи исполнителей, но и печати организаций, которые также как и подписи-картинки должны быть представлены в png-формате на прозрачном фоне.

Чтобы изменить в документе положение картинки со значения «в тексте» на значение «перед текстом» следует программно конвертировать картинку в объект «форма» методом ConvertToShape [11-13], а затем изменить тип формата.

\section{ЗАКЛЮЧЕНИЕ}

Ярким примером процессной модели управления в повседневной жизни является разработанный в РФ портал https://www. gosuslugi.ru, содержащий множество peaлизованных сервисов - бизнес-процессов. При этом архитектура сети «клиент-сервер» позволяет разработчикам, владеющим языками программирования (javascript, HTML, XML, PHP, C\#, Java, Python и пр. $[14,15])$ или различными CMS, создавать свои собственные сайты, наполнять их необходимыми бизнес-функциями, чтобы объединить их в бизнес-процессы. В данной статье продемонстрирован пример использования БП на платформе «1С:Предприятие 8.3», но для реализации механизма взаимодействия в сети необходимо установить «Тонкий клиент» $1 \mathrm{C}$ [16] или «Веб-клиент» [17] на машинах клиентов, а сервер базы данных 1С (платформа) должен иметь свой IP-адрес или воспользоваться возможностями облачной технологии $1 \mathrm{C}[18]$.

Автоматизация последовательности действий исполнителей БП упорядочивает их работу с документами (файлами) и ускоряет выполнение ими задач. Поэтому можно сказать, что бизнес-процессы добавляют ценности компании, как и другие функциональные компоненты прикладных решений. Они позволяют преодолеть функциональные разграничения прикладных решений, оперируя общими исходными данными, внутренними и внеш- 


\section{B. А. Лебедев}

ними документами всех уровней компании в режиме реального времени, что, в конечном итоге, приведет к ускорению всех операций с клиентами и оптимизации расходов.

\section{СПИСОК ЛИТЕРАТУРЫ}

1. Вивек, К. Внедрение SAP R/3.Руководство для менеджеров и инженеров/ К. Вивек. - Пер. с англ. П.А. Панов - М. : Компания АйТи, 2005. - 511 с.

2. SAP ABAP 4 Tutorial - Режим доступа: http://sapabap-4.blogspot.com - (Дата обращения: 21.04.2019).

3. Кречмер, Р. Разработка приложений SAP R/3 на языке АВАР/4/ Р. Кречмер, В. Вейс. М.: изд. Лори, 1998. - 335 с.

4. Программные продукты фирмы «1С». Режим доступа: http://1c.ru/rus/products/1c/ default.jsp. - (дата обращения: 21.04.2019).

5. Путивцева, Н. П. Решение задачи выбора российских корпоративных информационных систем с использованием метода анализа иерархий/ Н. П. Путивцева [и др.] // Вестник Воронеж. гос. ун-та. Сер. Системный анализ и информационные технологии. 2017. - № 4. - С. 85-91.

6. Бизнес-процессы. - Режим доступа: http://v8.1c.ru/erp/doc8corp/business.htm. (Дата обращения: 21.04.2019).

7. Гончаров, Д. И. Решение специальных прикладных задач в «1С:Предприятии 8.2» / Д. И. Гончаров, Е. А. Хрусталева - М. : 1С-Паблишинг, 2012. - $300 \mathrm{c}$.

8. Радченко, М. Г. 1С: Предприятие 8.3. Практическое пособие разработчика. Примеры и типовые приемы /М. Г. Радченко. - М.: 1С-Паблишинг, 2013. - 964 с.

9. Профессиональная разработка в системе 1С:Предприятие 8.3. / Ажеронок В. А. [и др.]. - М. : 1С-Паблишинг, 2013. - 808 с.

Лебедев В.А. - канд. техн. наук, доцент кафедры Экономической информатики ИНЭК УГАТУ.

E-mail: lav129@yandex.ru
10. Разработка управляемого интерфейса / Ажеронок В. А. [и др.]. - М. : 1С-Паблишинг, 2013. - $728 \mathrm{c}$.

11. Работа с файлами (картинками) в интерфейсе Такси. - Режим доступа: https:// infostart.ru/public/195003/. - (Дата обращения: 21.04.2019).

12. Два способа вставить изображение (штрих-код) в документ Word.Application. Режим доступа: https://club.directum.ru/ post/1124. - (Дата обращения: 21.04.2019).

13. 1C8. Пример работы с файлом MS Word и макетом типа ActiveDocument. - Режим доступа: http://j008.ru/ps/027_ActiveDocument. (Дата обращения: 21.04.2019).

14. Лебедев, В. А. Практикум применения технологий Microsoft в веб-проектах. (Электронное пособие) / В. А. Лебедев. Свидетельство о регистрации электронного ресурса №20766. ОФЭРНиО 5.02.2015г., 1225 с. Режим доступа: https://cloud.mail.ru/ public/7vxQ/uDtUuhMvE (или https://cloud. mail.ru/public/9dmV/JBK4u85Y8) - (Дата обращения: 21.04.2019).

15. Автоматизированная информационная система учета и мониторинга учебного процесса в вузе в условиях балльно-рейтинговой системы / А. И. Жданов [и др.] // Вестник Воронеж. гос. ун-та. Сер. Системный анализ и информационные технологии. - 2018. № 3. - С. 146-154.

16. Тонкий клиент. - Режим доступа: http://v8.1c.ru/overview/Term_000000124.htm. - (Дата обращения: 21.04.2019).

17. Веб-клиент. - Режим доступа: http:// v8.1c.ru/overview/Term_000000125.htm.

(Дата обращения: 21.04.2019)

18. Облачные технологии. - Режим доступа: http://v8.1c.ru/overview/Term_000000803. htm. - (Дата обращения: 21.04.2019). 


\title{
AUTOMATIC SIGNING OF ELECTRONIC DOCUMENTS IN BUSINESS PROCESSES OF APPLIED SOLUTIONS OF THE PLATFORM «1C: ENTERPRISE 8.3»
}

\begin{abstract}
V. A. Lebedev
Institute of Economics and Management of Ufa State Aviation Technical University

Annotation. It is proposed to develop business processes with automatic sight of documents on the platform «1C: Enterprise 8.3» for various sectors of the economy and spheres of activity of organizations, using the programming language 1C, SQL query language and VBA language office applications. As a result, it is expected to increase the reliability of storage of electronic documents and reduce the time of document management in organizations, which will effectively solve the problems of the digital economy of the Russian Federation.

Keywords: Applied solutions of 1C: Enterprise, business processes, tasks, maps of the route, the layout of the Active document, events, handlers events.
\end{abstract}

Lebedev V. A. - Associate Professor of the Chair of Economic Informatics INEC USATU.

E-mail:lav129@yandex.ru 